\title{
Mechanism of Anesthetic Toxicity: Metabolism, Reactive Oxygen Species, Oxidative Stress, and Electron Transfer
}

\author{
Peter Kovacic $^{1}$ and Ratnasamy Somanathan ${ }^{2}$ \\ ${ }^{1}$ Department of Chemistry and Biochemistry, San Diego State University, San Diego, CA 92182, USA \\ ${ }^{2}$ Centro de Graduados e Investigación del Instituto Tecnológico de Tijuana, Apdo postal 1166, 22500 Tijuana BC, Mexico
}

Correspondence should be addressed to Peter Kovacic, pkovacic@sundown.sdsu.edu

Received 13 September 2011; Accepted 11 October 2011

Academic Editors: D. Karakitsos and A. Mizutani

Copyright (c) 2011 P. Kovacic and R. Somanathan. This is an open access article distributed under the Creative Commons Attribution License, which permits unrestricted use, distribution, and reproduction in any medium, provided the original work is properly cited.

\begin{abstract}
There is much literature on the toxic effects of anesthetics. This paper deals with both the volatiles and locals. Adverse effects appear to be multifaceted, with the focus on radicals, oxidative stress (OS), and electron transfer (ET). ET functionalities involved are quinone, iminoquinone, conjugated iminium, and nitrone. The non-ET routes involving radicals and OS apparently pertain to haloalkanes and ethers. Beneficial effects of antioxidants, evidently countering OS, are reported. Knowledge at the molecular level should aid in devising strategies to combat the adverse effects.
\end{abstract}

\section{Introduction}

Toxic effects are a common response to many physiologically active substances including anesthetics. This paper deals with the mechanism of toxicity associated with anesthetics, both volatile, intravenous, and local. Generally, two pathways appear to be involved, namely, formation of reactive oxygen species (ROS), by redox cycling and electron transfer (ET), and ROS generation by non-ET routes. The latter pathway pertains to haloalkanes, ethers, and ethanol, whereas the former includes propofol, midazolam, and ketamine. Metabolites from the anesthetics appear to be the active agents.

The preponderance of bioactive substances or their metabolites incorporates ET functionalities, which, we believe, play an important role in physiological responses, examples of which include the following: quinones (or phenolic precursors), metal complexes (or complexors), nitroso and hydroxylamine metabolites from $\mathrm{ArNO}_{2}$ and $\mathrm{ArNH}_{2}$ [1], and conjugated imines (or iminium species). In vivo redox cycling of such entities with oxygen can occur, giving rise to OS through generation of ROS, for example, hydrogen peroxide, hydroperoxides, and superoxide. In some cases, ET results in interference with normal electrical effects, such as that which occurs in respiration or neurochemistry. Generally, active entities possessing ET groups display reduction potentials in the physiologically responsive range, that is, more positive than $-0.5 \mathrm{~V}$. ET, ROS, and OS have been increasingly implicated in the mode of action of many toxins, (toxicants), such as the following: reproductive toxins [2], nephrotoxins [3], hepatotoxins [4], cardiovascular toxins [5], nerve toxins [6], mitochondrial toxins [7], abused drugs [8], immune toxins [9], pulmonary toxins [10], dermal toxins [11], ototoxins [12], eye toxins [13], thyroid toxins [14], carcinogens [15], and also in other categories, such as human illnesses [16]. The quinone class includes propofol; conjugated iminium pertains to midazolam, whereas the less well-known nitroxide derives from ketamine.

It should be recognized that physiological action is often multifaceted. Hence, there is brief discussion of other toxic modes of action for anesthetics.

\section{Haloalkanes}

2.1. Chloroform. Chloroform was used as an anesthetic from the mid 1800s to about 1900. Other halocarbons came into use as replacements based on superior properties. Organ toxicity of chloroform involves the liver and kidney, in addition to developmental toxicity and teratogenicity [3].

Metabolism resembles that of carbon tetrachloride (Scheme 1) [15]. The pathway can also be applied to 


$$
\mathrm{Cl}_{3} \mathrm{CH} \stackrel{-\mathrm{H}^{\bullet}}{\longrightarrow} \mathrm{Cl}_{3} \mathrm{C}^{\bullet} \stackrel{\mathrm{O}_{2}}{\longrightarrow} \mathrm{Cl}_{3} \mathrm{COO} \stackrel{+\mathrm{H}^{\bullet}}{\longrightarrow} \mathrm{Cl}_{3} \mathrm{COOH} \stackrel{\mathrm{e}}{\longrightarrow} \mathrm{Cl}_{3} \mathrm{CO}^{-}+\mathrm{HO}^{\bullet}
$$

Scheme 1: Metabolism of chloroform.

related halohydrocarbons and ethers discussed below. It is reasonable to relate widespread toxicity to generation of ROS.

2.2. Halothane. Two pathways involving metabolism occur [17], one of which generates free radicals. Oxidation produces trifluoroacetyl chloride, an electrophilic reactive intermediate capable of covalently binding to proteins. Clinical use is now limited due to metabolism-associated liver toxicity. Halothane, chlorotrifluoromethane, is often used as an inhaled anesthetic [18]. Liver damage has been observed in patients. The damage may result from metabolites. ESR studies resulted in radical detection which may arise from the methylene group. Reaction of the carbon radical with oxygen could lead to a hydroperoxide, a likely precursor of the hydroxyl radical. Metabolism of halothane is known to generate a free radical [19]. Theoretically, this reactive species may be involved in hepatic disorders. The increase in superoxide production by halothane is correlated with its activation of protein kinase C [20]. The scheme is similar to that of chloroform (Scheme 1).

\section{Ethers}

3.1. Ethyl Ether. This ether was used in the 1800s as an anesthetic [21]. However, use was discontinued partly due to odor and flammability. Studies were performed on metabolism which yielded acetaldehyde and ethanol as products [22]. The ether was found to undergo an oxygen uptake in rat liver microsomal membrane [23]. These observations are in line with the oxidative metabolism outlined in Scheme 2 which entails initial conversion to a carbon radical followed by oxidation to hydroperoxide with decomposition to the metabolites. The hydroxyl radical could play a role in toxicity. The neurotoxic effects may involve ROS, such as lipid peroxides [24]. SOD activity increases as a defensive measure. Adverse effects of ethanol and acetaldehyde are presented in the ethanol section. The mechanism (Scheme 2 ) is supported by electron paramagnetic resonance study involving a nitrone as the spin trap [25]. The spectrum revealed the presence in rats of 1-ethoxyethyl radicals from the reaction mixture of diethyl ether and ferrous ions. Similar mechanisms may be operating for halogenated ethers (see below).

3.2. Other Haloethers. A mechanism similar to that for chloroform and ethyl ether can be used for this category which includes isoflurane and sevoflurane, commonly used in clinical anesthesis (see Figure 1).

3.3. Desflurane. Human biotransformation of desflurane has been characterized in vitro and in vivo [26]. Major metabolites are potentially toxic fluoride and trifluoroacetyl chloride

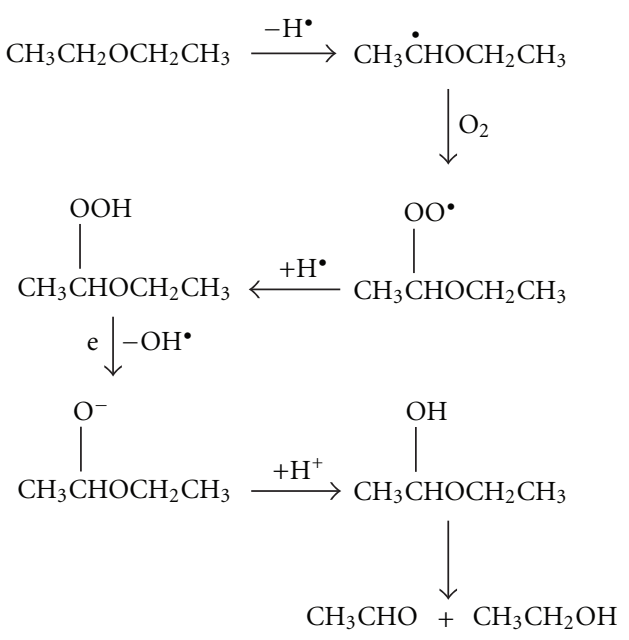

Scheme 2: Metabolism of ethyl ether.

which may bind to tissues in protein with detrimental results [26].

\section{Ethanol}

Although not widely used as an anesthetic, there are reports dealing with this property [27-29]. Metabolic steps have been delineated (Scheme 3) [15, 30]. Toxicity has been attributed mainly to ROS and acetaldehyde $[15,30]$.

\section{Propofol}

This anesthetic has received attention in connection with addiction among anesthesiologists and, more recently, the death of Michael Jackson. Six years ago, a novel unifying hypothesis was advanced for addiction and toxicity of abused drugs involving electron transfer (ET) [8]. One of the principal ET agents is the quinone group which is often generated metabolically. Appreciable numbers of abused drugs appear to function by the quinone route, including amphetamine, methamphetamine, ecstasy, morphine, heroin, phenobarbital, and aspirin. Recently, two additional members were added to the quinone category, namely, mescaline [31] and psilocybin [32].

Various reports on metabolism of propofol provide insight concerning action mechanism [33]. Analysis of products from oxidative metabolism revealed the presence of 2,6-diisopropyl-1,4-quinone (Figure 2) [34], in addition to the quinone dimer (diphenoquinone) (Figure 3) [35]. More specifically, it is reasonable to focus on involvement of ET processes and electrical effects in the central nervous system. The negatively charged electrons in motion create an electrical field. The radical anion semiquinone provides 


$\begin{array}{ccc}\mathrm{CHCl}_{2} \mathrm{CF}_{2} \mathrm{OCH}_{3} & \mathrm{CHClFCF}_{2} \mathrm{OCHF}_{2} & \mathrm{CF}_{3} \mathrm{CHClOCHF}_{2} \\ \text { Methoxyflurane } & \text { Enflurane } & \text { Isoflurane } \\ \mathrm{CH}_{2} \mathrm{FOCH}\left(\mathrm{CF}_{3}\right)_{2} & \mathrm{CF}_{3} \mathrm{CF}_{2} \mathrm{OCHF}_{2} & \\ \text { Sevoflurane } & \text { Desflurane } & \end{array}$

FIgURE 1: Structures of haloethers.

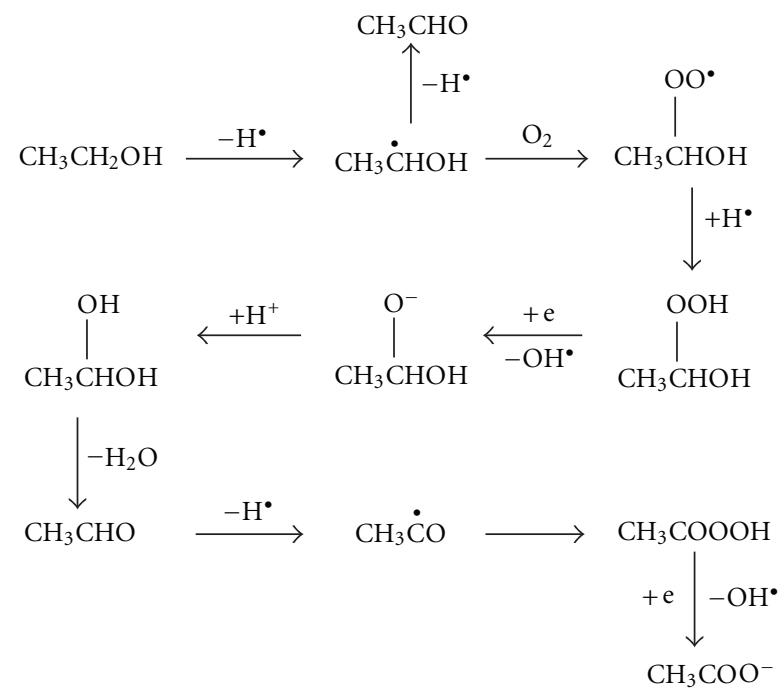

Scheme 3: Metabolism of ethanol.<smiles>CC(C)C1=CC(=O)C=C(C(C)C)C1=O</smiles>

FIGURE 2: 2,6-Diisopropyl-1,4-quinone.

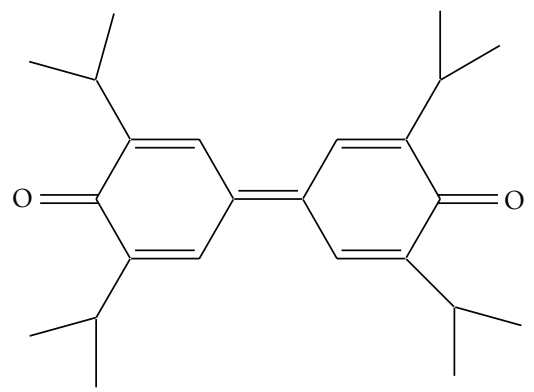

Figure 3: Propofol diphenoquinone.

molecular electrostatic potential. Since ET by quinone is often associated with generation of reactive oxygen species, these radicals, at low levels, may also play a role. At high concentrations, toxicity could result [8]. There has been scant attention paid to action mode at the molecular level.<smiles>Cc1ncc2n1-c1ccc(Cl)cc1C(c1ccccc1F)=NC2</smiles>

FIgURE 4: Midazolam.

\section{Midazolam}

Midazolam (Figure 4), a benzodiazepine (BZ), is the most commonly used one of its class in anesthetic medicine. Intravenous anesthetics are usually quite safe [36]. However, toxicity has been reported, such as seizures-like activity and paradoxical reactions.

In relation to mode of action, BZs are known to influence the activity of all major areas of the central nervous system (CNS) particularly the limbic structures. Presumably, they exert their effects through binding with protein receptors 


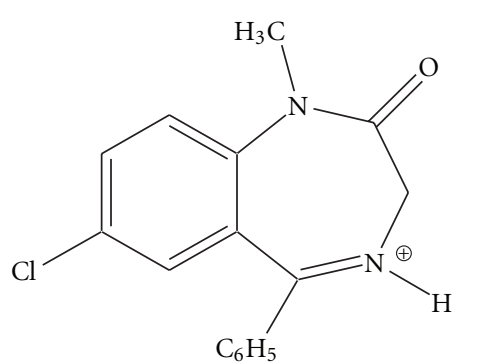

FIGURE 5: Protonated diazepam (Valium).

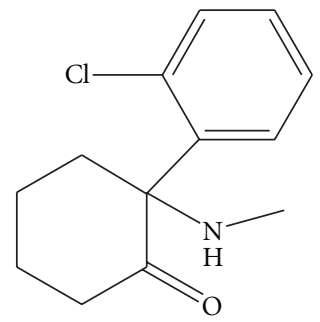

Figure 6: Ketamine.

within the CNS and are intimately involved with GABAergic neurotransmission. A 1986 article advanced a novel ET mechanism for BZ action [37]. BZs are protonated by weak acids to give iminium ions, such as in Figure 5, for diazepam which exhibit appreciable increases in reduction potential. Theoretical studies support such protonation during binding with protein [37]. Reversible electron uptake has been shown to occur with some protonated BZ drugs. The reduction potentials are of the same orders of magnitude as for other biologically active compounds.

\section{Ketamine}

Ketamine (Figure 6), a general anesthetic, which is usually injected, is also used for sedation, analgesis, and treatment of bronchospasm or depression. Studies have been made on treatment of drug addiction and pain control. Adverse effects have been noted. There is also use as recreational drug.

Investigations point to involvement of ROS-OS in bioaction. Findings suggest that ketamine inhibits relaxation by the extracellular production of superoxide [38]. The drug decreases GSH levels in prooxidant effects [39]. Results indicate that lipid peroxidation and protein oxidation were affected by subanesthetic doses of ketamine in cerebral structure [40].

Various reports exist on mode of action. Ketamine is a noncompetitive NMDA receptor antagonist [41]. This receptor opens in response to binding by glutamate, and blockade is believed to mediate the analgesic effects of the anesthetic [42]. At high level doses, binding also occurs to opioid and sigma receptors [43].

A 1998 article casts important light on mechanism of ketamine action in which spin trapping technique was used [44]. When the drug was added to liver microsomes and $\mathrm{NADPH}$, a nitroxide radical (Figure 7) derived from the

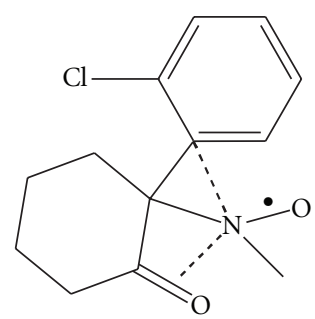

Figure 7: Ketamine nitroxide.

anesthetic was detected. Similar results were obtained during ketamine oxidation by hydrogen peroxide in a tungsten-catalyzed reaction, or in a Fenton system. The stable nitroxide radical produces an EPR spectrum in the absence of the trapping agent.

Studies with related compounds provide evidence that the nitroxide can play a role in ET-ROS-OS and toxicity. An article on cocaine metabolism is highly relevant [45]. Cocaine is mainly metabolized by two distinct pathways in humans. The major transformation consists of hydrolysis of the ester groups, which is apparently not important in the toxic manifestations. The minor route (Scheme 4) is an oxidative one involving the amine moiety, which has attracted most attention relative to some toxic responses. Possible metabolites participating in the effects of $\mathbf{4}(\mathbf{a})$, in addition to the drug itself, are norcocaine $4(\mathrm{c})$, norcocaine nitroxide 4(d), N-hydroxynorcocaine 4(e), norcocaine nitrosonium 4(f), cocaine iminium 4(b), and formaldehyde.

Oxidative metabolism of 4 (a) yields norcocaine $4(\mathrm{c})$, evidently via the iminium derivative $\mathbf{4}(\mathbf{b})$. Microsomes in the brain and liver further oxidize $\mathbf{4}(\mathrm{c})$ to the nitroxide $\mathbf{4}(\mathrm{d})$. This radical is stabilized by delocalization over $\mathrm{O}$ and $\mathrm{N}$, and apparently by intramolecular interaction with n-electrons on the ester substituent. The transannular effect which has ample precedent might well apply to other radical species involved in redox cycling in the cocaine system, as well as to magnitude of the reduction potential.

Another metabolite is the N-hydroxy derivative 4(e) (an hydroxylamine) which arises from 4 (c) by a sequence comprising electron and proton uptake in a reversible manner. The duo of $4(\mathrm{c})$ and $\mathbf{4 ( d )}$ apparently bears resemblance to the one comprising aromatic nitroso compound (ArNO)aromatic hydroxylamine (ArNHOH) which redox cycles with participation of the ArNHO ${ }^{\bullet}$ radical.

An alternate redox cycle entails electron loss by $4(\mathrm{~d})$ to form nitrosonium cation 4(f) (oxoammonium) reversibly. This aspect has been the object of less attention.

These data can logically be applied to the nitroxide metabolite of ketamine as a vehicle for generation of toxic ROS which is presented in other sections. The nitroxide radical may be stabilized by delocalization with the carbonyl group, analogous to cocaine, and also with the aromatic nucleus as treated below for PCP.

Theoretical studies on PCP provide useful insight [46, 47]. It is well established that oxidative metabolism of PCP 8(a) leads to the iminium species $\mathbf{8}(\mathbf{b})$. Although $\mathbf{8}(\mathbf{b})$ is not directly conjugated with the aromatic nucleus, cyclic 


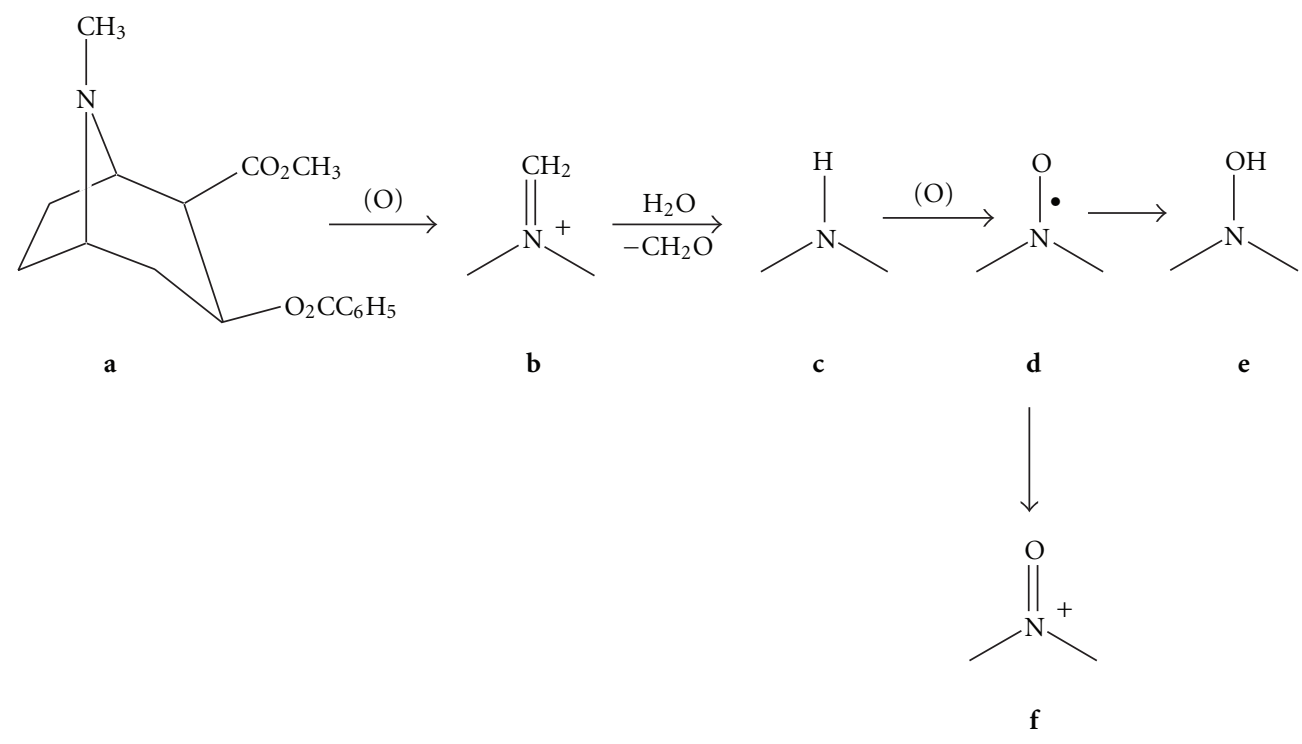

Scheme 4: Cocaine metabolism.<smiles>[Z]C1(c2ccccc2)CCCCC1</smiles>

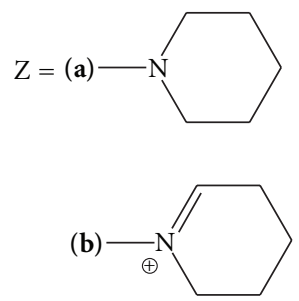

(8)

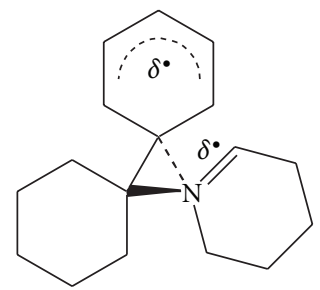

(8c)

Figure 8: Phencyclidine, iminium metabolite, and iminium radical.

voltammetry studies indicated interactive stabilization of the reduced species. Recently, computational studies were performed on the energetics of electron uptake by $\mathbf{8}(\mathbf{b})$ with respect to conformation [46]. In relation to the reduced species, thermodynamic preferences were found for conformations similar to that present in PCP bound to the active site. The through-space delocalization is depicted in $\mathbf{8}(\mathbf{c})$. The calculations suggest that a factor in the biological responses may be ET by the iminium metabolite Figure 8 .

\section{Nitrous Oxide}

Nitrous oxide, $\mathrm{N}_{2} \mathrm{O}$, also called laughing gas, exhibits anesthetic and analgesic effects [48]. Its use began in 1884 and has continued to the present, including recreational use. The gas is known to produce adverse effects, such as neurotoxicity,<smiles>CCN(CC)CC(=O)Nc1c(C)cccc1C</smiles>

Figure 9: Lidocaine.

similar to other NMDA antagonists. Harmful reproductive effects may arise in pregnancy due to chronic exposure.

Nitrous oxide can undergo oxidation to nitric oxide (NO). Actions in the CNS are similar to those of NO [48]. Some of the effects may result from oxidation to NO which exhibits both beneficial and harmful actions $[49,50]$.

\section{Local Anesthetics}

Amine-amide compounds comprise a principal class in local anesthetics. Important information is provided by metabolic studies (Scheme 5) carried out with lidocaine (Figure 9) [51].

2,6-Xylidine has been identified as a metabolite in urine of rats, guinea pigs, dogs, and humans given lidocaine. The amine has been shown in samples of milk from bovines during surgery and breast milk samples of human donor who received lidocaine during dental work. In addition, the substance has been identified as a major metabolite in human liver slices in vitro. 2,6-Xylidine is a metabolite excreted in the urine of humans exposed to etidocaine. Aromatic hydroxylation is also involved in the metabolism as illustrated in Scheme 5. In the case of 2,6-xylidine, the nitrogen of the amino group and the para position on the aromatic ring are the two possible sites for the initial CYP-mediated monooxygenation, leading to the production of $\mathrm{N}-(2,6-$ dimethylphenyl)hydroxylamine (DMHA) and 4-amino-3,5dimethylphenol (DMAP), respectively. DMHA has potential 


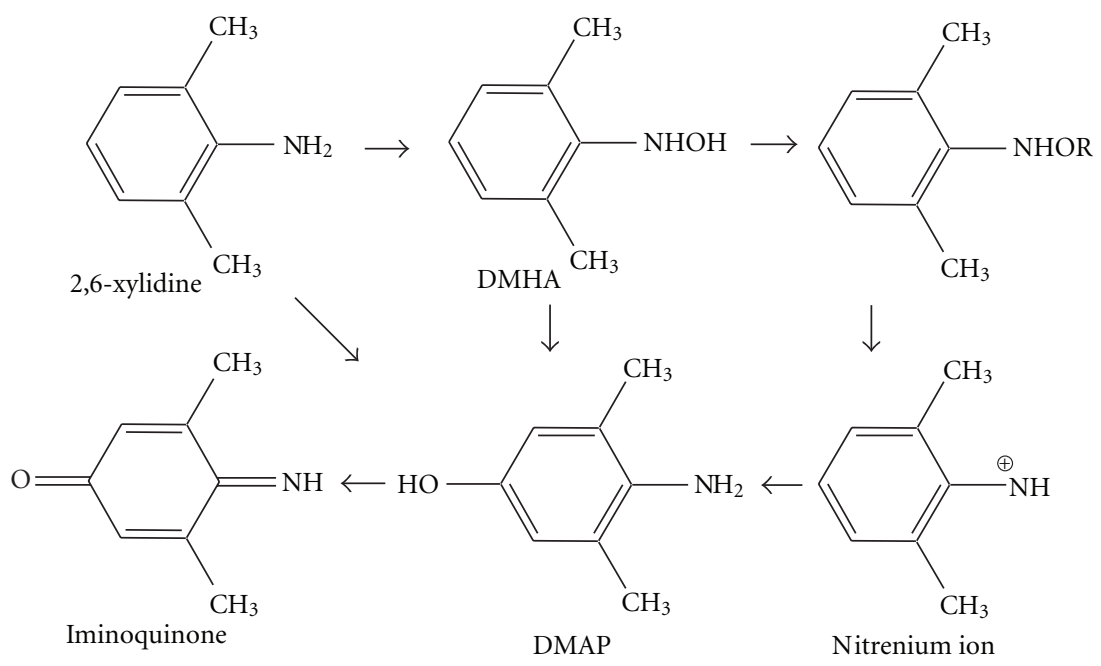

Scheme 5: Metabolism of 2,6-xylidine.

to react with DNA either directly or after esterification. DMAP is potentially genotoxic by a mechanism involving nonenzymatic oxidation to an iminoquinone, which is a strong electrophile. Indirect evidence for the formation of $\mathrm{N}$ hydroxylated aromatic amines in vivo can be obtained from the detection of hemoglobin adducts, which are formed by covalent binding of the bioactivated amines with residues of the $\beta$-chain of hemoglobin.

In rats and dogs DMAP is a major 2,6-xylidine metabolite found in urine. Studies using recombinant human CYPs and human liver microsomes have shown that DMAP is the only metabolic product at micromolar concentration of 2,6xylidine, whereas at nanomolar concentrations DMHA was a substantial product. DMHA can be rearranged to DMAP, and CYP2E1 was shown to catalyze this reaction. 2,6Xylidine-hemoglobin adduct levels were elevated in human patients receiving lidocaine treatment for local anesthesia or cardiac arrhythmias, which is indicative that DMHA is a metabolite of lidocaine in man. Alternatively, the hydroxylamine product may undergo oxidation to the nitroso derivative with subsequent redox cycling and ROS formation (see Introduction).

Aromatic hydroxylation of lidocaine and mepivacaine was also investigated in rats and humans [52]. 4-Hydroxy2,6-xylidine accounts for more than half of the lidocaine dose in humans. There is similarity to metabolism of acetaminophen which also yields an iminoquinone [2]. There is rise in ROS peroxide formation and GSH depletion which have been linked to toxicity.

In relation to adverse effects of lidocaine, these are rare when the drug is used properly [53]. Exposure in excess mainly results in adverse CNS and cardiovascular effects.

Relevant studies were performed with bupivacaine, closely related in structure to lidocaine. There is strong evidence for neurotoxicity of local anesthetics, especially through apoptosis [54]. Bupivacaine was found to induce apoptosis in cells via ROS. Biochemical analysis with this drug indicates that myopathies could be explained, in part, by OS and alteration of mitochondrial energetics [55].
A protective effect was exerted by the $\mathrm{AO} \mathrm{N}$-acetylcysteine against reticulum stress and apoptosis in skeletal muscle [56]. The anesthetic induced ROS production, OS, and activation of caspases. Since the structures of bupivacaine, ropivacaine, and levobupivacaine are similar to that of lidocaine, it is reasonable to assign a similar mode of action.

A review deals with local anesthetic toxicity with emphasis on molecular mechanisms and treatment strategies [57]. High levels of activity are exhibited in the CNS and cardiovascular system.

\section{ROS, OS, and AO Properties}

There are possible health hazards from long term exposure to volatile anesthetics [58]. Minimizing occupational exposure is important for protection from health hazards. AO supplementation is recommended. A study reveals that volatile anesthetics may exacerbate oxidant injury to endothelium [59]. A similar study showed theeffect on OS due to occupational exposure. The authors suggest that operating room personnel should take $\mathrm{AO}$ supplement to minimize the effect [60].

Volatile anesthetics have been shown to generate ROS in the heart [61]. The review addresses source of the ROS and the means by which they induce cardiac injury. A similar study showed that anesthetic preconditioning triggered by ROS improves mitochondrial function after ischemia [62].

Rats treated with ether showed signs of OS [63]. There was $30-60 \%$ loss of total GSH. Lipid peroxidation products increased appreciably. The changes are attributed to ROS and OS. The toxic effects were noted in the liver and kidney.

Myocardial dysfunction after coronary bypass surgery is well-known phenomenon that may significantly affect postoperative prognosis. Not only the adequacy of the surgical revasculrization, but also the effectiveness of myocardial preservation will determine the maintenance of ventricular function and thus the postoperative outcome. Anestheticinduced postconditioning is a phenomenon whereby a brief exposure of the myocardium to a volatile halogenated 
anesthetic, at the very onset of reperfusion, markedly reduces myocardial injury following prolonged ischemia. Desflurane, propofol, and sevoflurane provide cardioprotection [64, 65]. A similar study showed that sevoflurane-induced AMPK activation protects the heart against ischemia and reperfusion injury [66-68].

Preconditioning with desfurane or sevoflurane protects rat cardiomyocytes from OS-induced cell death. Scavenging of ROS abolishes the preconditioning effect of both anesthetics and attenuates anesthetic-induced mitochondrial uncoupling, suggesting a crucial role of ROS in anesthetic-induced preconditioning and implying that ROS act upstream of mitochondrial uncoupling [69]. Desflurane exhibits greater effect on stimulation of ROS production and mitochondrial uncoupling than sevoflurane. A study showed that volatile anesthetic, desflurane, reduces vitamin $\mathrm{E}$ level in blood of operative patients via OS [70]. ROS formation was observed during sevoflurane exposure, and protein kinase $\mathrm{C}$ and ROS are known to have a role in anesthetic preconditioning [71].

Exposure of rats to desflurane and sevoflurane and analysis of the tissues of brain, kidney, and lung showed increase in malondialdehyde and decrease in superoxide dismutase and glutathione peroxidase due to OS and ROS [72].

A review documents involvement of halothanes in OS [73]. Increased oxidant damage might be related to free radical formation during metabolism [74]. Thiobarbituric acid reactive substances were increased. Results showed depletion of GSH and vitamins $\mathrm{C}$ and $\mathrm{E}$ in the liver [75]. A simultaneous increase in the levels of malonaldehyde occurred. It appears that increased production of free radicals overwhelm the AO defenses in the liver. Reports show lipid peroxidation in various membranes [76].

Prolonged exposure of developing mammals to general anesthetics enhances neuronal toxicity [77]. Neuronal cell death is mainly apoptotic. Evidence for the role of OS in the toxicity arises from application of OS blockers. Prevention of neuronal cell death by catalase and SOD supports the contention that ROS are involved.

A comparative study involving propofol and desfurane in $\mathrm{OS}$ and $\mathrm{AO}$ activities indicted that the latter anesthetic induced systemic increase in OS, with increased lipid peroxidation, and suppression of vitamin $\mathrm{E}$ [78].

Propofol, chemically similar to the endogenous antioxidant $\alpha$-tocopherol, has been reported to have antioxidant properties [79]. Intravenous anesthetic propofol affords significant augmentation of $\mathrm{AO}$ defense to the pulmonary endothelium, in response to ischemia-reperfusion injury [80]. Propofol was shown to inhibit lactoperoxidase, an enzyme that catalyzes the oxidation of halides and pseudohalides at the expense of hydrogen peroxide and to generate products with antimicrobial activity [81].

\section{Other Mechanisms and Toxicity}

Although our focus is on oxidative reactions leading to formation of toxic ROS, it should be recognized that other metabolic pathways can be importantly involved. Toxic degradation products are formed from a range of old and modern anesthetic agents [82]. The common element in the formation of degradation products is the reaction of the agent with bases in the carbon dioxide absorbents in the apparatus circuit. A common adverse reaction is nephrotoxicity. In sevoflurane, fluoride ions are produced by oxidative defluorination by cytochrome P450 system [83]. These ions are potentially toxic, for example, to the kidney, at high concentrations, pointing to the importance of gas flow rate.

A 1999 review deals with metabolism and toxicity of anesthetics [84]. An example comprises reaction of sevoflurane with soda lime in the apparatus circuit [83]. Hydrolysis of the primary fluoride yields a fluoride and a hemiacetal which readily decomposes to a secondary alcohol and formaldehyde.

A review deals with metabolism of fluorine-containing drugs, mainly volatile anesthetics. There is discussion of metabolic defluorination which can readily occur during biotransformation [17]. The process favors formation of the fluoride ion which can be highly toxic. Inhalation anesthetics reversibly inhibit mitochondrial ET at the levels of the enzyme NADH dehydrogenase [85]. The organ toxicities of the class related to their intermediary or final metabolites. In a study of harmful effects of local anesthetics, central neural blockade accounts for more than $70 \%$ of regional anesthesia procedures [86]. An article deals with organs toxicity of inhaled anesthetics [87].

\section{Other Aspects}

Mode of action of local anesthetics involves electrophysiology [88]. There is interaction between receptor and drug involving ionic, dipolar, and van der Waals forces. Studies with the carbonyl-tert-amine class indicate that the neutral form readily penetrates the membrane. Once inside, this entity undergoes protonation to the ionic species with associated electrostatic field.

\section{Conclusion}

This paper provides a unifying mechanism for various classes of anesthetics, based on metabolic formation of ROS-OS. In some cases the ROS are generated by ET agents, as in the case of lidocaine. There is considerable supporting literature. The proposed mode of action is supported by beneficial effects of AOs. Knowledge of fundamental aspects at the molecular level can translate into practical results.

\section{Abbreviations}

$\begin{array}{ll}\text { ET: } & \text { Electron transfer } \\ \text { ROS: } & \text { reactive oxygen species } \\ \text { AO: } & \text { antioxidant } \\ \text { BZ: } & \text { benzodiazepine } \\ \text { EPR: } & \text { electron paramagnetic resonance } \\ \text { PCP: } & \text { phencyclidine } \\ \text { GSH: } & \text { glutathione } \\ \text { DMHA: } & \text { N-(2,6-dimethylphenyl)hydroxylamine } \\ \text { DMAP: } & \text { 4-amino-3,5-dimethylphenol. }\end{array}$




\section{Acknowledgment}

Editorial assistance by Thelma Chavez is acknowledged.

\section{References}

[1] P. Kovacic and R. Somanathan, "Novel, unifying mechanism for aromatic primary-amines (therapeutics, carcinogens and toxins): electron transfer, reactive oxygen species, oxidative stress and metabolites," MedChemComm, vol. 2, no. 2, pp. 106-112, 2011.

[2] P. Kovacic and J. D. Jacintho, "Reproductive toxins: pervasive theme of oxidative stress and electron transfer," Current Medicinal Chemistry, vol. 8, no. 7, pp. 863-892, 2001.

[3] P. Kovacic, A. Sacman, and M. Wu-Weis, "Nephrotoxins: widespread role of oxidative stress and electron transfer," Current Medicinal Chemistry, vol. 9, no. 8, pp. 823-847, 2002.

[4] G. Poli, K.H. Cheeseman, M. U. Dianzani, and T. F. Slater, Free radicals in the Pathogenesis of Liver Injury, Pergmon Press, New York, NY, USA, 1989.

[5] P. Kovacic and L. A. Thurn, "Cardiovascular toxicity from the perspective of oxidative stress, electron transfer, and prevention by antioxidants," Current Vascular Pharmacology, vol. 3, no. 2, pp. 107-117, 2005.

[6] P. Kovacic and R. Somanathan, "Neurotoxicity: the broad framework of electron transfer, oxidative stress and protection by antioxidants," Current Medicinal Chemistry - Central Nervous System Agents, vol. 5, no. 4, pp. 249-258, 2005.

[7] P. Kovacic, R. S. Pozos, R. Somanathan, N. Shangari, and P. J. O’Brien, "Mechanism of mitochondrial uncouplers, inhibitors, and toxins: focus on electron transfer, free radicals, and structure-activity relationships," Current Medicinal Chemistry, vol. 12, no. 22, pp. 2601-2623, 2005.

[8] P. Kovacic and A. L. Cooksy, "Unifying mechanism for toxicity and addiction by abused drugs: electron transfer and reactive oxygen species," Medical Hypotheses, vol. 64, no. 2, pp. 357366, 2005.

[9] P. Kovacic and R. Somanathan, "Integrated approach to immunotoxicity: electron transfer, reactive oxygen species, antioxidants, cell signaling, and receptors," Journal of Receptors and Signal Transduction, vol. 28, no. 4, pp. 323-346, 2008.

[10] P. Kovacic and R. Somanathan, "Pulmonary toxicity and environmental contamination: radicals, electron transfer, and protection by antioxidants," Reviews of Environmental Contamination and Toxicology, vol. 201, pp. 41-69, 2009.

[11] P. Kovacic and R. Somanathan, "Dermal toxicity and environmental contamination: electron transfer, reactive oxygen species, oxidative stress, cell signaling, and protection by antioxidants," Reviews of Environmental Contamination and Toxicology, vol. 203, pp. 119-138, 2010.

[12] P. Kovacic and R. Somanathan, "Ototoxicity and noise trauma: electron transfer, reactive oxygen species, cell signaling, electrical effects, and protection by antioxidants: Practical medical aspects," Medical Hypotheses, vol. 70, no. 5, pp. 914-923, 2008.

[13] P. Kovacic and R. Somanathan, "Unifying mechanism for eye toxicity: electron transfer, reactive oxygen species, antioxidant benefits, cell signaling and cell membranes," Cell Membranes and Free Radical Research, vol. 1, pp. 56-69, 2008.

[14] P. Kovacic and C. Edwards, "Integrated approach to the mechanisms of thyroid toxins: electron transfer, reactive oxygen species, oxidative stress, cell signaling, receptors, and antioxidants," Journal of Receptors and Signal Transduction, vol. 30, no. 3, pp. 133-142, 2010.
[15] P. Kovacic and J. D. Jacintho, "Mechanisms of carcinogenesis: focus on oxidative stress and electron transfer," Current Medicinal Chemistry, vol. 8, no. 7, pp. 773-796, 2001.

[16] B. Halliwell and J. M. C. Gutteridge, Free Radicals in Biology and Medicine, Oxford University Press, New York, NY, USA, 1999.

[17] B. K. Park, N. R. Kitteringham, and P. M. O’Neill, “Metabolism of fluorine-containing drugs," Annual Review of Pharmacology and Toxicology, vol. 41, pp. 443-470, 2001.

[18] B. Halliwell and J. M. C. Gutteridge, Free radicals in Biology and Medicine, Oxford University Press, New York, NY, USA, 2000.

[19] M. Morio, O. Yuge, and K. Fujii, "Biotransformation and toxicity of inhalational anaesthetics," Canadian Journal of Anaesthesia, vol. 37, no. 1, pp. Scxvi-Scxxiii, 1990.

[20] M. Tsuchiya, E. Okimasu, W. Ueda, M. Hirakawa, and K. Utsumi, "Halothane, an inhalation anesthetic, activates protein kinase C and superoxide generation by neutrophils," FEBS Letters, vol. 242, no. 1, pp. 101-105, 1988.

[21] D. Cox, R. DeRienz, R. A. J. Phipps, B. Levine, A. Jacobs, and D. Fowler, "Distribution of ether in two postmortem cases," Journal of Analytical Toxicology, vol. 30, no. 8, pp. 635-637, 2006.

[22] C. P. Chengelis and R. A. Neal, "Microsomal metabolism of diethyl ether," Biochemical Pharmacology, vol. 29, no. 2, pp. 247-248, 1980.

[23] R. A. Peters and M. Shorthouse, "An alkyl etherase in rat liver," Journal of Physiology, vol. 252, no. 2, pp. 537-545, 1975.

[24] S. Awasthi, P. Kakkar, P. N. Viswanathan, and R. Bharadwaj, "Effect of anaesthetic ether on lipid peroxidation and superoxide dismutase isozymes of young and adult rat brain," Indian Journal of Experimental Biology, vol. 27, no. 7, pp. 647-649, 1989.

[25] K. Kumamoto, T. Hirai, S. Kishioka, and H. Iwahashi, "Identification of 1-ethoxyethyl radicals in the reaction of ferrous ions with serums from rats exposed to diethyl ether," Toxicology Letters, vol. 154, no. 3, pp. 235-239, 2004.

[26] E. D. Kharasch, "Metabolism and toxicity of the new anesthetic agents," Acta Anaesthesiologica Belgica, vol. 47, no. 1, pp. 7-14, 1996.

[27] M. Hong, M. K. Choi, and J. Lee, "The anesthetic action of ethanol analyzed by genetics in Caenorhabditis elegans," Biochemical and Biophysical Research Communications, vol. 367, no. 1, pp. 219-225, 2008.

[28] C. J. Fox, H. Liu, and A. D. Kaye, "The anesthetic implications of alcoholism," International Anesthesiology Clinics, vol. 49, no. 1, pp. 49-65, 2011.

[29] B. Wolfson and B. Freed, "Influence of alcohol on anesthetic requirements and acute toxicity," Anesthesia and Analgesia, vol. 59, no. 11, pp. 826-830, 1980.

[30] P. Kovacic and R. Somanathan, "Alcohol mechanism: metabolism, cell signaling, toxicity, addiction, prevention, therapy, and beneficial effects," in New Research on Alcohol Abuse and Alcoholism, E. Y. Brozner, Ed., chapter 4, pp. 49102, Nova Science Publishers, New York, NY, USA, 2006.

[31] P. Kovacic and R. Somanathan, "Novel, unifying mechanism for mescaline in the central nervous system: electrochemistry, catechol redox metabolite, receptor, cell signaling and structure activity relationships," Oxidative Medicine and Cellular Longevity, vol. 2, no. 4, pp. 181-190, 2009.

[32] P. Kovacic, "Unifying electron transfer mechanism for psilocybin and psilocin," Medical Hypotheses, vol. 73, no. 4, pp. 626$631,2009$. 
[33] P. Kovacic, "Unifying electron transfer mechanism for addiction involvement by the anesthetic propofol," Medical Hypotheses, vol. 74, no. 1, p. 206, 2010.

[34] P. Favetta, J. Guitton, C. S. Degoute, L. Van Daele, and R. Boulieu, "High-performance liquid chromatographic assay to detect hydroxylate and conjugate metabolites of propofol in human urine," Journal of Chromatography B, vol. 742, no. 1, pp. 25-35, 2000.

[35] M. T. Baker, M. S. Gregerson, S. M. Martin, and G. R. Buettner, "Free radical and drug oxidation products in an intensive care unit sedative: propofol with sulfite," Critical Care Medicine, vol. 31, no. 3, pp. 787-792, 2003.

[36] T. G. Short and Y. Young, "Toxicity of intravenous anaesthetics," Best Practice and Research: Clinical Anaesthesiology, vol. 17, no. 1, pp. 77-89, 2003.

[37] P. W. Crawford, P. Kovacic, N. W. Gilman, and M. D. Ryan, "Charge transfer mechanism for benzodiazepine (BZ) action. Correlation of reduction potential of BZ iminium with structure and drug activity," Bioelectrochemistry and Bioenergetics, vol. 16, no. 3, pp. 407-426, 1986.

[38] A. Kohjitani, T. Miyawaki, M. Funahashi, H. Higuchi, R. Matsuo, and M. Shimada, "Ketamine and midazolam differentially inhibit nonadrenergic noncholinergic lower esophageal sphincter relaxation in rabbits: role of superoxide anion and nitric oxide synthase," Anesthesiology, vol. 98, no. 2, pp. 449458, 2003.

[39] F. C. C. da Silva, M. do Carmo de Oliveira Cito, M. I. G. da Silva et al., "Behavioral alterations and pro-oxidant effect of a single ketamine administration to mice," Brain Research Bulletin, vol. 83, no. 1-2, pp. 9-15, 2010.

[40] L. de Oliveira, C. M. dos S. Spiazzi, T. Bortolin et al., "Different sub-anesthetic doses of ketamine increase oxidative stress in the brain of rats," Progress in Neuro-Psychopharmacology and Biological Psychiatry, vol. 33, no. 6, pp. 1003-1008, 2009.

[41] S. A. Lipton, "Paradigm shift in neuroprotection by NMDA receptor blockade: memantine and beyond," Nature Reviews Drug Discovery, vol. 5, no. 2, pp. 160-170, 2006.

[42] B. Sinner and B. M. Graf, "Ketamine," Handbook of experimental pharmacology, no. 182, pp. 313-333, 2008.

[43] R. Kortekaas, R. P. Maguire, A. van Waarde, K. L. Leenders, and P. H. Elsinga, "Despite irreversible binding, PET tracer [11C]-SA5845 is suitable for imaging of drug competition at sigma receptors - the cases of ketamine and haloperidol," Neurochemistry International, vol. 53, no. 1-2, pp. 45-50, 2008.

[44] L. A. Reinke, Y. Kotake, D. R. Moore, and A. A. Nanji, "Free radical formation during ketamine anesthesia in rats: a cautionary note," Free Radical Biology and Medicine, vol. 24, no. 6, pp. 1002-1006, 1998.

[45] P. Kovacic, "Role of oxidative metabolites of cocaine in toxicity and addiction: oxidative stress and electron transfer," Medical Hypotheses, vol. 64, no. 2, pp. 350-356, 2005.

[46] K. N. Kirschner, C. Van Dyke, P. Kovacic, and J. P. Bowen, "Computational studies on electron transfer by the iminium metabolite of phencyclidine (PCP)," Journal of Molecular Structure: THEOCHEM, vol. 498, pp. 167-179, 2000.

[47] P. Kovacic and R. Somanathan, "Clinical physiology and mechanism of dizocilpine (MK-801): electron transfer, radicals, redox metabolites and bioactivity," Oxidative Medicine and Cellular Longevity, vol. 3, no. 1, pp. 13-22, 2010.

[48] D. E. Emmanouil and R. M. Quock, "Advances in understanding the actions of nitrous oxide," Anesthesia progress, vol. 54, no. 1, pp. 9-18, 2007.

[49] J. D. Jacintho and P. Kovacic, "Neurotransmission and neurotoxicity by nitric oxide, catecholamines, and Glutamate: unifying themes of reactive oxygen species and electron transfer," Current Medicinal Chemistry, vol. 10, no. 24, pp. 26932703, 2003.

[50] P. Kovacic and R. Somanathan, "Integrated approach to nitric oxide in animals and plants (mechanism and bioactivity): cell signaling and radicals," Journal of Receptors and Signal Transduction, vol. 31, no. 2, pp. 111-120, 2011.

[51] E. Tydén, H. Tjälve, and P. Larsson, "Metabolic activation of 2,6-xylidine in the nasal olfactory mucosa and the mucosa of the upper alimentary and respiratory tracts in rats," Toxicological Sciences, vol. 81, no. 2, pp. 263-272, 2004.

[52] J. Thomas and P. Meffin, "Aromatic hydroxylation of lidocaine and mepivacaine in rats and humans," Journal of Medicinal Chemistry, vol. 15, no. 10, pp. 1046-1049, 1972.

[53] D. Jackson, A. H. Chen, and C. R. Bennett, "Identifying true lidocaine allergy," The Journal of the American Dental Association, vol. 125, no. 10, pp. 1362-1366, 1994.

[54] C. J. Park, S. A. Park, T. G. Yoon, S. J. Lee, K. W. Yum, and H. J. Kim, "Bupivacaine induces apoptosis via ROS in the Schwann cell line," Journal of Dental Research, vol. 84, no. 9, pp. 852$857,2005$.

[55] K. Nouette-Gaulain, C. Jose, X. Capdevila, and R. Rossignol, "From analgesia to myopathy: when local anesthetics impair the mitochondrion," International Journal of Biochemistry and Cell Biology, vol. 43, no. 1, pp. 14-19, 2011.

[56] O. Galbes, A. Bourret, K. Nouette-Gaulain et al., "Nacetylcysteine protects against bupivacaine-induced myotoxicity caused by oxidative and sarcoplasmic reticulum stress in human skeletal myotubes," Anesthesiology, vol. 113, no. 3, pp. 560-569, 2010.

[57] J. M. Dippenaar, "Local anesthetic toxicity," SAJAA, vol. 13, pp. 23-28, 2007.

[58] C. H. Kindler and C. S. Yost, "Two-pore domain potassium channels: new sites of local anesthetic action and toxicity," Regional Anesthesia and Pain Medicine, vol. 30, no. 3, pp. 260274, 2005.

[59] M. E. Johnson, J. C. Sill, C. B. Uhl, T. J. Halsey, and G. J. Gores, "Effect of volatile anesthetics on hydrogen peroxideinduced injury in aortic and pulmonary arterial endothelial cells," Anesthesiology, vol. 84, no. 1, pp. 103-116, 1996.

[60] H. Türkan, A. Aydin, and A. Sayal, "Effect of volatile anesthetics on oxidative stress due to occupational exposure," World Journal of Surgery, vol. 29, no. 4, pp. 540-542, 2005.

[61] L. G. Kevin, E. Novalija, and D. F. Stowe, "Reactive oxygen species is mediators of cardiac injury and protection: the relevance to anesthesia practice," Anesthesia and Analgesia, vol. 101, no. 5, pp. 1275-1287, 2005.

[62] E. Novalija, L. G. Kevin, B. S. Henry, H. B. S. Eells, and D. F. Stowe, "Anesthetic preconditioning triggered by reactive oxygen species improves mitochondrial function after ischemia," Anesthesiology, vol. 95, abstract A104, 2001.

[63] P. T. Liu, P. A. Kentish, A. M. Symons, and D. V. Parke, "The effects of ether anaesthesia on oxidative stress in rats-dose response," Toxicology, vol. 80, no. 1, pp. 37-49, 1993.

[64] S. Lemoine, C. Buléon, R. Rouet et al., "Bradykinin and adenosine receptors mediate desflurane induced postconditioning in human myocardium: role of reactive oxygen species," BMC Anesthesiology, vol. 10, article no. 12, 2010.

[65] S. G. De Hert, S. Cromheecke, P. W. Ten Broecke et al., "Effects of propofol, desflurane, and sevoflurane on recovery of myocardial function after coronary surgery in elderly highrisk patients," Anesthesiology, vol. 99, no. 2, pp. 314-323, 2003.

[66] R. R. Lamberts, G. Onderwater, N. Hamdani et al., "Reactive oxygen species-induced stimulation of 5'amp-activated 
protein kinase mediates sevoflurane-induced cardioprotection," Circulation, vol. 120, no. 1, pp. S10-S15, 2009.

[67] K. Tanaka, D. Weihrauch, L. M. Ludwig, J. R. Kersten, P. S. Pagel, and D. C. Warltier, "Mitochondrial adenosine triphosphate-regulated potassium channel opening acts as a trigger for isoflurane-induced preconditioning by generating reactive oxygen species," Anesthesiology, vol. 98, no. 4, pp. 935-943, 2003.

[68] K. Tanaka, L. M. Ludwig, J. R. Kersten, P. S. Pagel, and D. C. Warltier, "Mechanisms of cardioprotection by volatile anesthetics," Anesthesiology, vol. 100, no. 3, pp. 707-721, 2004.

[69] F. Sedlic, D. Pravdic, M. Ljubkovic, J. Marinovic, A. Stadnicka, and Z. J. Bosnjak, "Differences in production of reactive oxygen species and mitochondrial uncoupling as events in the preconditioning signaling cascade between desflurane and servoflurane," Anesthesia \& Analgesia, vol. 109, pp. 405-411, 2009.

[70] F. Eroglu, L. Yavuz, B. G. Ceylan et al., "New volatile anesthetic, desflurane, reduces vitamin e level in blood of operative patients via oxidative stress," Cell Biochemistry and Function, vol. 28, no. 3, pp. 211-216, 2010.

[71] E. Novalija, L. G. Kevin, A. K. S. Camara, Z. J. Bosnjak, J. P. Kampine, and D. F. Stowe, "Reactive oxygen species precede the $\varepsilon$ isoform of protein kinase $\mathrm{C}$ in the anesthetic preconditioning signaling cascade," Anesthesiology, vol. 99, no. 2, pp. 421-428, 2003.

[72] H. Türkan, A. Aydin, A. Sayal, A. Eken, C. Akay, and B. Karahalil, "Oxidative and antioxidative effects of desflurane and sevoflurane on rat tissue in vivo," Arhiv za Higijenu Rada i Toksikologiju, vol. 62, no. 2, pp. 113-119, 2011.

[73] K. G. Karageuzyan, "Halothane anesthesis in oxidative stress," in the International Symposium on the Application of the Theory of Metabolic Regulation to Pain, pp. 330-334, Stepanakert, Azerbaijan, 1998.

[74] A. Yesilkaya, Z. Ertug, Yegin, M. Melikoglu, and O. K. Baskurt, "Deformability and oxidant stress in red blood cells under the influence of halothane and isoflurane anesthesia," General Pharmacology, vol. 31, no. 1, pp. 33-36, 1998.

[75] E. A. El-Bassiouni, M. M. Abo-Ollo, M. H. Helmy, S. Ismail, and M. I. A. Ramadan, "Changes in the defense against free radicals in the liver and plasma of the dog during hypoxia and/or halothane anaesthesia," Toxicology, vol. 128, no. 1, pp. 25-34, 1998.

[76] A. Yesilkaya and P. Dogan, "Halothane induced lipid peroxidation on human erythrocyte membranes," Turkish Journal of Medical Sciences, vol. 16, no. 4, pp. 275-280, 1992.

[77] C. Wang, X. Zhang, F. Liu, M. G. Paule, and W. Slikker, "Anesthetic-induced oxidative stress and potential protection," TheScientificWorldJournal, vol. 10, pp. 1473-1482, 2010.

[78] B. G. Ceylan, F. Yilmaz, F. Eroglu, L. Yavuz, S. Gulmen, and H. Vural, "Oxidant and antixidant activities of different anesthetic techniques. Propofol versus desflurance," Saudi Medical Journal, vol. 30, no. 3, pp. 371-376, 2009.

[79] Z. Peng, M. Luo, S. Ye, G. Joynt, and L. Critchley, "The protective effects of propofol on vascular endothelial cells," Anesthesiology, vol. 96, abstract A58, 2002.

[80] I. V. Balyasnikova, D. E. Schwartz, V. L. Baughman, W. E. Hoffman, and S. M. Danilov, "Protective effect of propofol on reperfusion-induced lung microvascular injury," Anesthesiology, vol. 96, abstract A49, 2002.

[81] M. Şişecioğlu, M. Çankaya, I. Gülçin, and H. Özdemir, "The inhibitory effect of propofol on bovine lactoperoxidase," Protein and Peptide Letters, vol. 16, no. 1, pp. 46-49, 2009.
[82] M. W. Anders, "Formation and toxicity of anesthetic degradation products," Annual Review of Pharmacology and Toxicology, vol. 45, pp. 147-176, 2005.

[83] B. A. Gentz and T. P. Malan Jr., "Renal toxicity with sevoflurane: a storm in a teacup?" Drugs, vol. 61, no. 15, pp. 21552162, 2001.

[84] H. Bito, "Metabolism and toxicity of anesthetics," Japanese Journal of Anesthesiology, vol. 48, pp. S172-S179, 1999.

[85] J. D. Levitt, "The biochemical basis of anesthetic toxicity," Surgical Clinics of North America, vol. 55, no. 4, pp. 801-818, 1975.

[86] B. Cox, M. E. Durieux, and M. A. Marcus, "Toxicity of local anesthetics," Best Practice \& Research Clinical Anaesthesiology, vol. 17, pp. 111-136, 2003.

[87] J. G. Kenna and R. M. Jones, "The organ toxicity of inhaled anesthetics," Anesthesia and Analgesia, vol. 81, no. 6, pp. S51S66, 1995.

[88] P. Kovacic, R. S. Pozos, and C. D. Draskovich, "Unifying electrostatic mechanism for receptor-ligand activity," Journal of Receptors and Signal Transduction, vol. 27, no. 5-6, pp. 411431, 2007. 


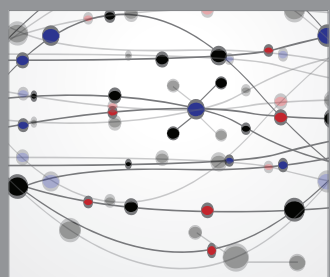

The Scientific World Journal
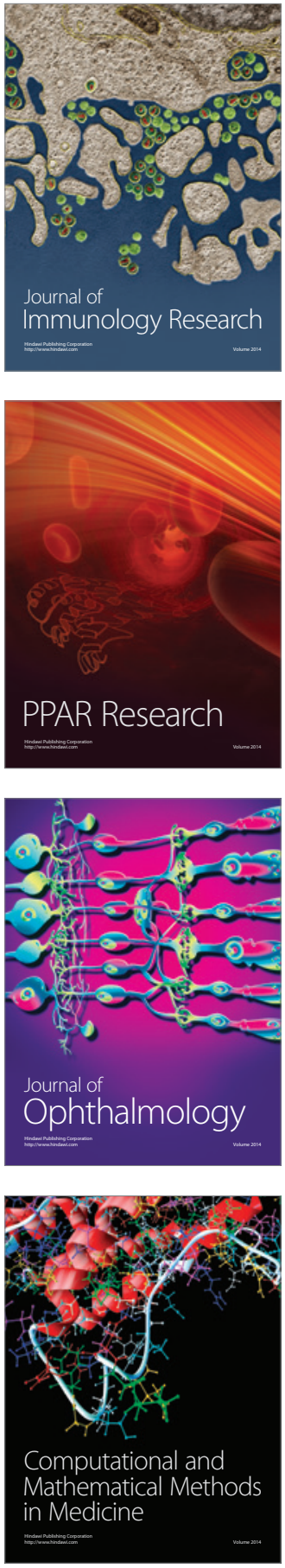

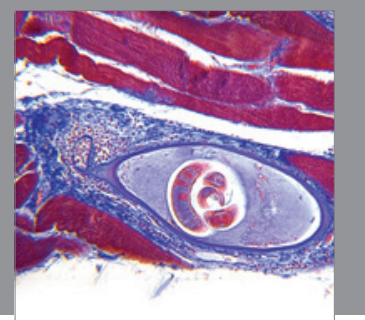

Gastroenterology

Research and Practice
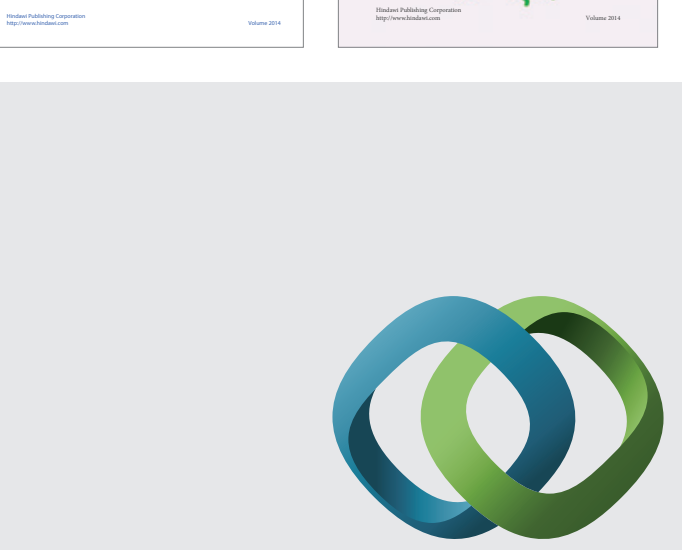

\section{Hindawi}

Submit your manuscripts at

http://www.hindawi.com
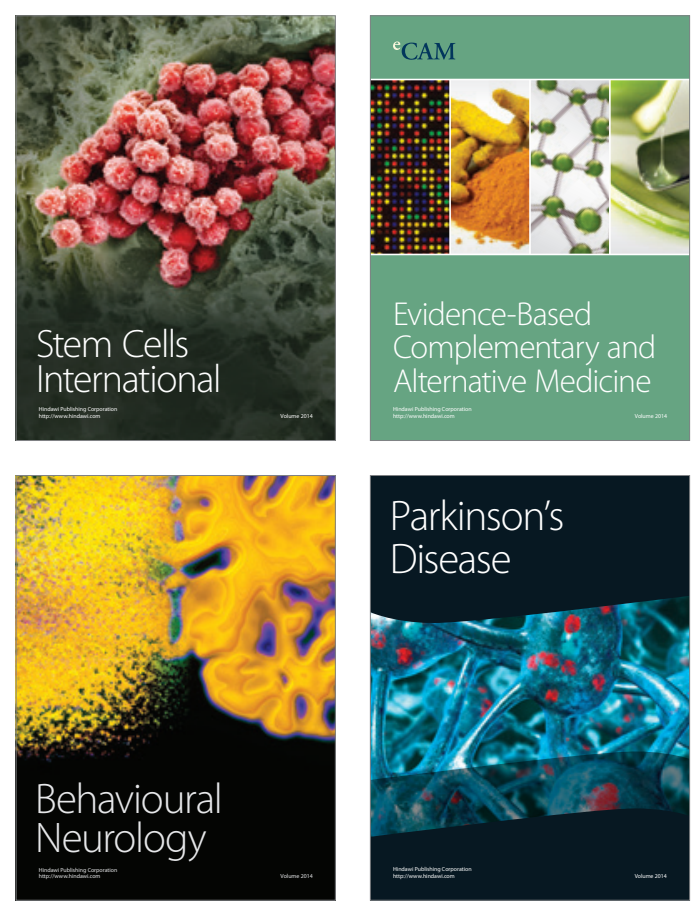

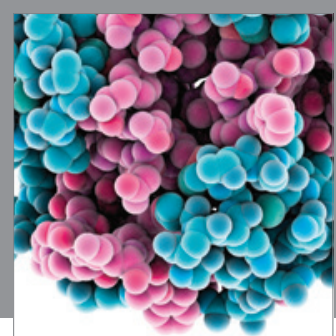

Journal of
Diabetes Research

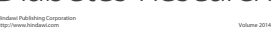

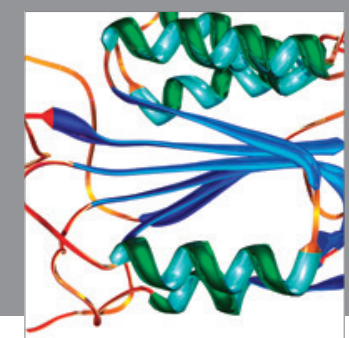

Disease Markers
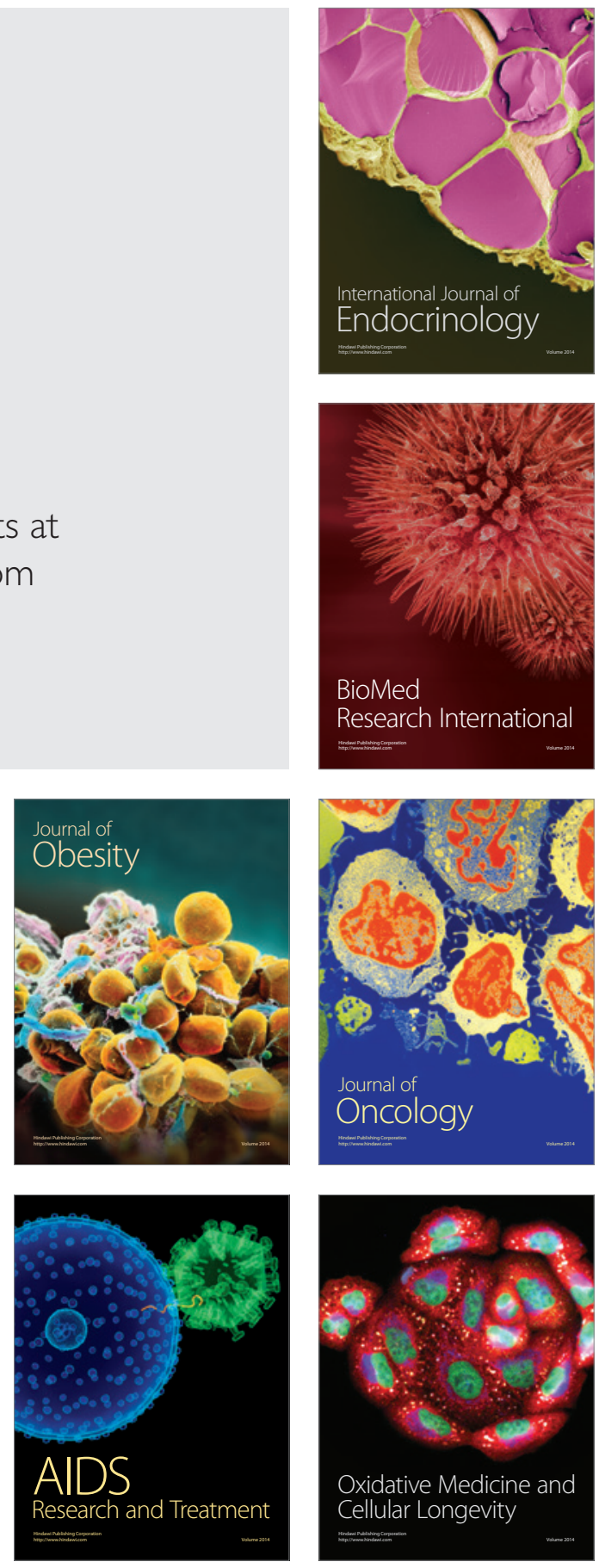